\title{
PENGEMBANGAN VIRTUAL REALITY SEBAGAI MEDIA PEMBELAJARAN PENGENALAN HEWAN MENGGUNAKAN AFRAME
}

\author{
Dimas Wahyu Wibowo', Eka Larasati $\mathrm{A}^{2}$, Ridwan Rismanto ${ }^{3}$ \\ Jurusan Teknologi Informasi, Politeknik Negeri Malang \\ 1'dimas.w@polinema.ac.id, ${ }^{2}$ Eka.Larasati@polinema.ac.id, ${ }^{3}$ rismanto@polinema.ac.id \\ (Artikel diterima: Oktober 2019, direvisi: September 2019, diterima untuk terbit: Januari 2020)
}

\begin{abstract}
Abstrak - Pada awal sejarah pendidikan, guru adalah satu-satunya sumber untuk memperoleh ilmu atau pelajaran. Dalam perkembangannya selanjutnya, sumber belajar atau ilmu bertambah dengan adanya buku. Tetapi dengan adanya perkembangan teknologi pembelajaran tidak lagi terikat sebatas guru dan buku. Teknologi pembelajaran dapat berupa visual dan audio sedangkan untuk penerapan teknologi ini dapat berupa Virtual Reality atau Augmented Reality. Dengan adanya perkembangan teknologi ini diharapkan menambah keminatan siswa untuk memperhatikan mata pelajaran tertentu. Karena dengan penerapan pembejaran tepat dapat membuat suasana kelas maupun kualitas siswa untuk menerima ilmu semakin baik. Pada beberapa tahun ini perkembangan javascript mulai meningkat salah satunya adalah A-frame. A-frame adalah sebuah web framework yang dibangun menggunakan kerangka three.js sehingga memungkinkan para developer untuk membangun virtual reality menggunakan web browser. Pada penelitian ini peneliti akan menerapkan web framewok A-frame ini untuk membuat sebuah aplikasi virtual reality sebagai media pembelajaran pengenalan hewan.
\end{abstract}

Kata kunci: A-Frame, Media Pembelajaran, Virtual Reality.

\section{Pendahuluan}

Pada awal sejarah pendidikan, guru adalah satusatunya sumber untuk memperoleh ilmu atau pelajaran. Dalam perkembangannya selanjutnya, sumber belajar atau ilmu bertambah dengan adanya buku. Tetapi dengan adanya perkembangan teknologi pembelajaran tidak lagi terikat sebatas guru dan buku. Teknologi pembelajaran dapat berupa visual dan audio sedangkan untuk penerapan teknologi ini dapat berupa Virtual Reality atau Augmented Reality. Dengan adanya perkembangan teknologi ini diharapkan menambah keminatan siswa untuk memperhatikan mata pelajaran tertentu. Karena dengan penerapan pembejaran tepat dapat membuat suasana kelas maupun kualitas siswa untuk menerima ilmu semakin baik.

Menurut Arsyad (2006) media pembelajaran dapat memenuhi tiga (3) fungsi utama apabila digunakan untuk perorangan, kelompok atau pendengar yang besar yaitu [1]:

- Memotivasi minat atau tindakan,

- Menyajikan informasi,

- Memberi instruksi

Disamping itu media juga mempunyai manfaat diantaranya:

- Pembejaran akan lebih menarik perhatian siswa sehingga dapat menumbuhkan motivasi belajar

- Bahan pembelajaran akan bemakna sehingga dapat lebih dipahami oleh mahasiswasertamemungkinkannya menguasai dan mencapai tujuan pembejaran.

- Metode belajar akan lebih bervariasi tidak semata-mata komunikasi verbal melalui penuturan kata-kata oleh guru sehingga peserta belajar tidak bosan dan guru tidak kehabisan tenaga.

Pada penelitian ini peneliti menggunakan Framework AFrame untuk menunjang pembuatan sebuah media pembelajaran. Untuk objek yang akan ditampilkan adalah beberapa hewan dalam bentuk 2D.

\section{Tinjauan Pustaka}

\section{A. Media}

Media adalah sarana yang digunakan untuk menyampaikan informasi atau pesan. Sedangkan menurut para ahli media itu:

- Menurut Gagne: media adalah berbagai komponen dalam lingkungan pembelajaran siswa yang dapat merangsang keinginan untuk belajar.

- Menurut Schram: media adalah teknologi pembawa pesan yang dapat digunakan untuk pembelajaran.

Secara umum media dapat dibagi menjadi:

- Media visual. Media visual ini mengandalkan indra penglihatan dan peraba. Contoh: foto, gambar, majalah, dan buku.

- Media audio. Media audio ini mengandalkan media pendengaran. Contoh: suara, musik, dan CD.

- Media audio visual. Media audio ini menggunakan media pendengaran dan penglihatan secara bersamaan. Contoh: televisi, VCD.

\section{B. Media Pembelajaran}

Media pembelajaran adalah segala sesuatu yang dapat menyalurkan pesan, merangsang pikiran, perasaan, dan kemauan peserta didik sehingga tercipta proses belajar mengajar yang menyenangkan. Tujuan dari penggunaan media pembelajaran adalah dapat memberikan kemudahan bagi peserta didik untuk memahami materi pembelajaran, menumbuhkan minat peserta didik terhadap suatu materi, memperjelas informasi, dan menciptakan suasana belajar yang interaktif.

Dengan demikian, dengan adanya media pembelajaran dapat membantu guru memfasilitasi kegiatan belajar mengajar agar proses belajar lebih mudah, memperjelas materi pembelajaran dengan beragam contoh yang konkret 
melalui media serta memfasilitasi interaksi dan memberi kesempatan praktek kepada siswa.

\section{Virtual Reality}

Virtual reality adalah teknologi yang dapat berinteraksi dengan suatu lingkungan yang disimulasikan oleh komputer. Virtual reality digunakan untuk menggambarkan lingkungan 3D yang dihasilkan oleh komputer dan dapat berinteraksi dengan seseorang. Contoh teknologi virtual reality yang cukup sederhana adalah Google Cardboard karena dibuat menggunakan kertas. Kelebihan dari virtual reality ini adalah pengguna dapat merasakan sensasi dunia nyata dalam dunia maya. Teknologi ini banyak diterapkan dalam beberapa bidang diantaranya kedokteran, pendidikan, arsitek, dan lain sebagainya. Virtual reality sangat membantu dalam mensimulasikan sesuatu yang sulit untuk dihadirkan secara langsung dalam dunia nyata. Virtual reality membawa pengguna melihat dunia semu, yang sebenarnya adalah gambar dinamis. Gambar dinamis tersebut adalah hasil dari rekayasa komputer melalui headphone atau speaker. Pengguna dapat mendengarkan suara yang nyata melalui headset, glove dan walker semua gerakan dipantau oleh sistem. sistem memberikan reaksi yang sesuai sehingga pengguna seolah merasakan dunia yang nyata baik secara fisik maupun psikologis.

\section{Grafis $2 D$}

Grafik komputer 2 dimensi biasa disebut dengan 2D atau bidang adalah bentuk dari benda yang memiliki panjang dan lebar. Grafik 2 Dimensi merupakan teknik penggambaran yang berpatokan pada titik koordinat sumbu x (datar) dan sumbu y (tegak). Agar dapat tampil dengan sempurna, gambar yang akan ditampilkan dengan teknik ini harus memiliki nilai koordinat $\mathrm{x}$ dan $\mathrm{y}$ minimum 0 dan maksimum sebesar resolusi yang digunakan.

\section{E. A-Frame}

A-Frame adalah teknologi baru dari Mozilla, yang memungkinkan Anda untuk membuat pengalaman 2D, Virtual Reality, Augmented Reality dan hanya dengan beberapa tag HTML. A-Frame Ini dibangun di atas WebGL, Three.js, dan beberapa Elemen Khusus, yang bagian dari standar

Komponen HTML. Khususnya Untuk pengembangan Augmented Reality Jerome Etienne membuat sebuah library javascript dengan nama ar.js untuk mempermudah pembuatan Augmented reality.

\section{Metodologi Penelitian}

\section{A. Tahapan Penelitian}

Metode pembuatan sistem ini menggunakan model waterfall. Model ini mengambil kegiatan proses dasar spesifiksasi, pengembangan, validasi, dan evolusi dan merepresentasikannya sebagai fase - fase proses yang berbeda seperti spesifikasi persyaratan, perancangan perangkat lunak, implementasi, pengujian, dan seterusnya. Adapun tahapan - tahapan berikut ini :

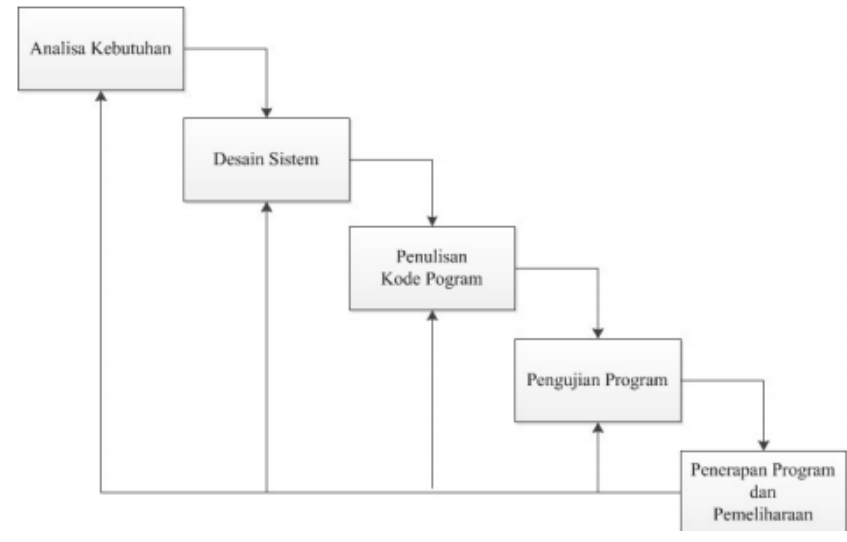

Gambar 1. Proses Tahapan Penelitian Waterfall

\section{B. Analisis Kebutuhan}

Tahap ini merupakan tahap awal yang digunakan untuk menganalisa kebutuhan apa saja

yang dibutuhkan sebagai syarat dalam mengimplementasikan framework A-Frame untuk membuat sebuah aplikasi virtual reality

\section{Desain Sistem}

Pembuatan aplikasi ini menggunakan framework javascript A-Frame dan menggunakan model hewan 2 dimensi yang nanti akan berjalan pada browser. Secara Umum diskripsi sistem adalah sebagai berikut :

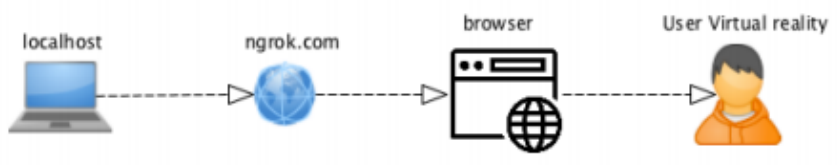

Gambar 2 Desain Sistem Virtual Reality

Pada gambar 2 dapat diketahui secara umum diskripsi sistem adalah

- Aplikasi berjalan pada localhost

- Agar user dapat mengakses localhost maka diperlukan ngrok. Ngrok adalah proxy server untuk membuat / membuka jaringan private melalui NAT atau firewall untuk menghubungkan localhost ke internet dengan tunnel yang aman.

- Jika berhasil maka localhost dapat diakses melalui browser menggunakan jaringan internet.

- User dapat menggunakan cardboard dan mengakses aplikasi menggunakan browser

Aplikasi ini selain menampilkan objek-objek hewan 2 dimensi dapat mengeluarkan suara-suara hewan tersebut. Pada pengembangan aplikasi virtual reality ini selain aplikasi dapat menampilkan objek 2 dimesi hewan diperlukan juga posisi,rotasi dan skala yang tepat agar terlihat menarik. Pada framework A-Frame menyediakan cara untuk mengatur posisi, rotasi dan skala objek hewan. Sehingga Proses perancangan meliputi

1. Menampilkan objek 2D

2. Mengatur posisi,rotasi dan skala objek 2D

3. Menambahkan environment

4. Menambahkan suara 


\section{Penulisan Kode Program}

Pada tahap ini setelah melakukan desain system aplikasi, kemudian direalisasikan dengan menggunakan kode - kode Bahasa pemograman yaitu HTML dan javascipt

\section{E. Pengujian Program}

Pada tahap ini dilakukan pengujian aplikasi secara menyeluruh yang telah dibuat menggunakan kode - kode Bahasa pemograman untuk dilakukan pengimplementasian pada aplikasi virtual reality menggunakan framework Aframe

\section{F. Penerapan program dan pemeliharaan}

Pada tahap terakhir ini, setelah setiap tahap dilakukan penerapan program dan pemeliharaan aplikasi yang berguna apabila terjadi berbagi error dan perubahan - perubahan sesuai dengan keinginan pengguna.

\section{G. Perancangan Sistem}

Pada perancangan Sistem ini ada beberapa hal yang menjadi factor utama agar aplikasi virtual reality menggunakan A-Frame dapat berjalan, antara lain: menampilkan objek 2D, Mengatur posisi, skala dan rotasi objek 2D, Menambahkan environment, dan menambahkan suara

\section{Menampilkan objek 2D}

Pada Perancangan awal adalah menampilkan beberapa objek hewan pada browser. Untuk menampilkan beberapa objek pada web browser, A-Frame telah menyediakan sebuah tag HTML untuk menampilkan gambar pada browser yaitu menggunakan tag HTML <a-image $></$ a-image $>$. Selain itu pada A-Frame menyediakan tag HTML asset yaitu $<$ a-asset $>$ $</ a-a s s e t>$ untuk menyimpan asset-asset yang nanti digunakan pada aplikasi ini. Untuk objek-objek 2D hewan disimpan pada asset dengan penamaan id yang unik dan nanti akan digunakan sebagai acuan objek mana yang akan ditampilkan pada web berdasarkan pada idnya, sebagai contoh seperti berikut:

\section{$<$ a-assets $>$}

<img id="lynx" crossorigin="anonymous"

$\mathrm{src}=" /$ penelitian (aset) / sound-

360 /animal/lynx.png" />

<img id="deer" crossorigin="anonymous"

$\mathrm{src}=" /$ penelitian (aset) / sound-

$360 /$ animal/rusa.png" />

<img id="gajah" crossorigin="anonymous"

src="/penelitian (aset)/sound-

360 /animal/gajah.png"

/>

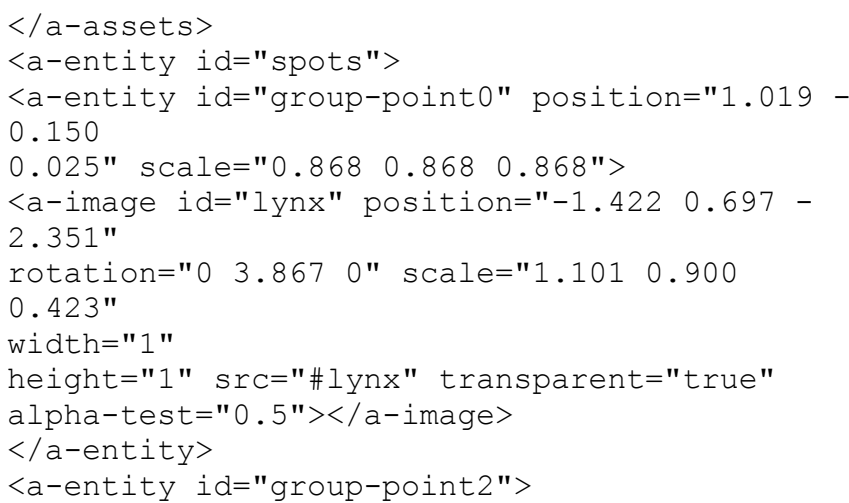

<a-image id="gajah" position="0.928 0.857 -

3.317 " scale="1.820 1 1" width="1" height="1" $\mathrm{src}=$ "\#gajah"

transparent="true" alpha-test="0.5" $></ a-$

image>
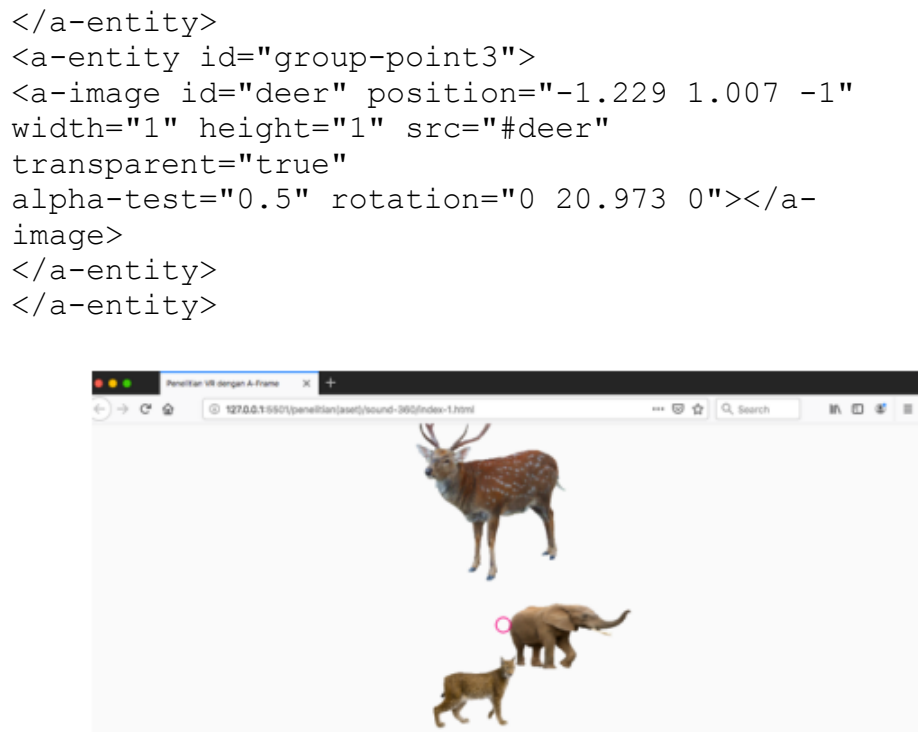

Gambar 3 Hasil menampilkan objek 2 Dimensi

\section{Mengatur posisi, skala dan rotasi objek 2D}

Pada Perancangan berikutnya adalah mengatur posisi pada objek mengatur position, scale, dan rotation objek hewan 2D agar terlihat rapi. Untuk mengset position, rotation dan scale maka dapat menggunakan inspector yang disediakan oleh A-Frame. Untuk menampilkan inspector pada web browser dapat menggunakan shortcut $\mathrm{Ctrl}+\mathrm{Alt}+\mathrm{I}$ sehingga pada halaman browser akan muncul seperti pada gambar 4 .

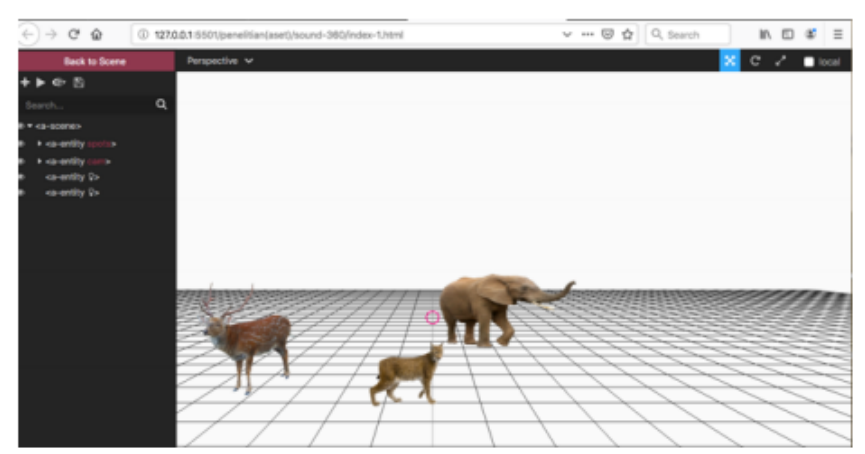

Gambar 4 Inspector

Pada inspector ini terdapat beberapa pilihan untuk mengatur objek berdasarkan posisi, skala dan rotasi. Untuk semua objek hewan dijadikan satu entity dengan nama id spots dan dimana didalamnya terdapat beberapa entity-entity yang mencerminkan objek hewan tersebut. 


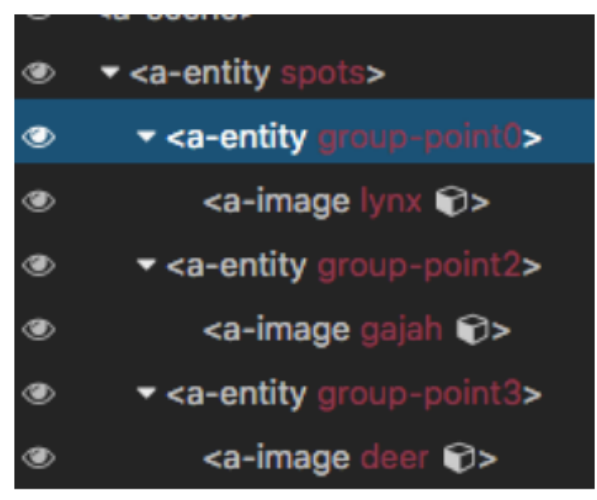

Gambar 5 Entity objek hewan

Pada inspector ini terdapat panah sumbu $\mathrm{x}, \mathrm{y}, \mathrm{z}$ dan informasi posisi, skala dan rotasi pada objek seperti pada gambar 6. Sehingga untuk mengatur objek baik posisi, skala dan rotasi dapat diatur dengan menggeser objek 2D dan nantinya informasi pada inspector akan berubah sesuai dengan posisi, rotasi dan skala sudah sesuai. Jika posisi, rotasi dan skala sudah ditentukan maka pada code disesuaikan.

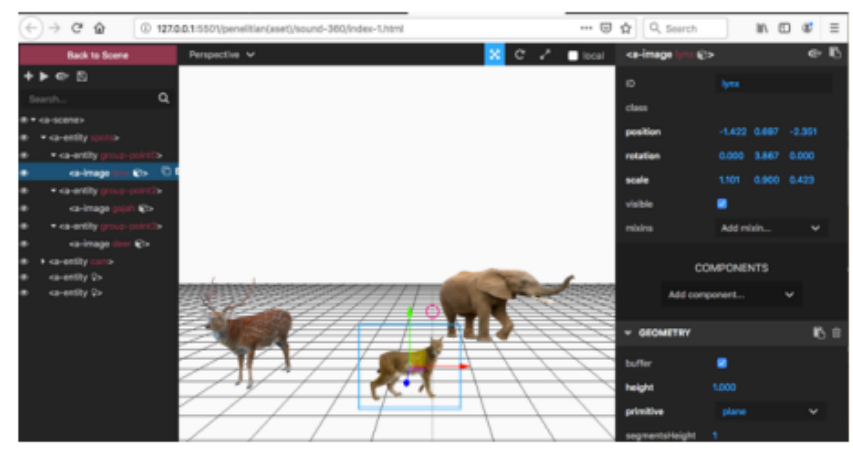

Gambar 6 informasi pada Inspector

\section{Menambahkan environment}

Untuk perancangan berikutnya adalah menambahkan environment berupa hutan. Untuk menambahkan background hutan maka diperlukan sebuah source aframe-enviromentcomponent yang diletakkan pada header dengan link sebagai berikut:

<script src="https://unpkg.com/aframeenvironment-componente1.1.0/dist/aframeenvironment-component.min.js" $></$ script $>$

Pada scene ditambah atribut background dan environment dengan value seperti berikut:

<a-scene background="color: \#FAFAFA"

environment="preset: forest">

Sehingga hasilnya seperti pada gambar 7 .

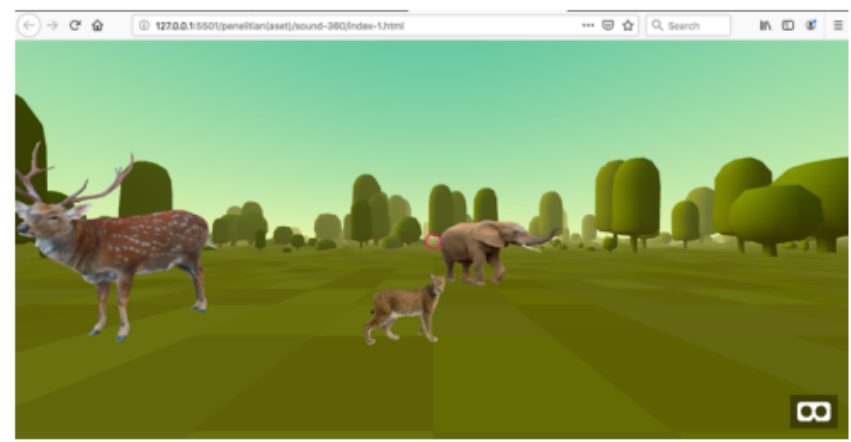

Gambar 7 Environment hutan

\section{Menambahkan suara}

Perancangan berikutnya menambahkan suara pada objek hewan 2D. Untuk menambahkan suara menggunakan library howler.js. Libray howler.js adalah sebuah library yang digunakan untuk memainkan sebuah suara menggunakan javascript.

\section{HASIl dan PEMbahasan}

\section{A. Menampilkan Objek 2D}

Untuk menampilkan objek 2D diperlukan asset berupa gambar objek 2 Dimensi dari hewan. Untuk menampilkan gambar pada A-Frame diperlukan tag html asset $(<\mathrm{a}-$ asset $><$ /a-asset $>$ ), dimana asset ini nanti mempunyai atribut id, crossorigin, dan src. Asset ini nantinya berada pada struktur body dan pada tag scene. Selain gambar 2 dimensi diperlukan juga ikon sound. Sehingga pada asset terdapat asset antara lain asset gambar 2 dimensi objek hewan dan asset icon sound. Pada tiap-tiap objek 2 Dimensi hewan diberi nama seperti pada gambar 8 .

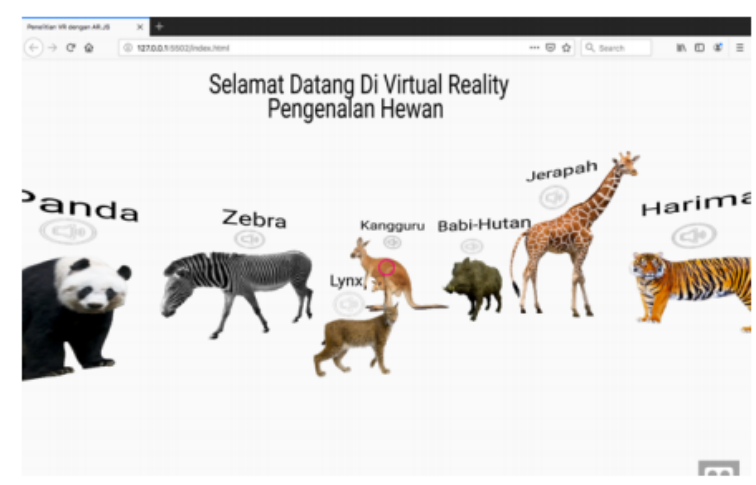

Gambar 8 objek-objek hewan beserta nama hewan dan icon sound

Pada gambar 2 Dimensi dan icon sound telah diset background transparent, hal ini dilakukan agar objek 2 Dimensi hewan dan icon sound dapat terlihat menyatu dengan background.

\section{B. Mengatur posisi, rotasi dan skala hewan}

Pada proses pengaturan posisi, rotasi dan skala hewan dilakukan beberapa uji coba, hal ini dilakukan agar mendapatkan suasana hutan yang menarik. Dari beberapa uji coba didapatkan sebuah tabel posisi, skala dan rotasi pada 18 objek hewan yang ditampilkan pada web browser.

Tabel 1. Tabel Posisi Objek Hewan berdasarkan

\begin{tabular}{|r|l|l|l|l|}
\multicolumn{5}{|c|}{ sumbu x, y z } \\
\hline no & Hewan & $\mathrm{x}$ & $\mathrm{y}$ & $\mathrm{z}$ \\
\hline 1 & lynx & 1.019 & -0.150 & 0.025 \\
\hline 2 & zebra & -0.409 & 1.145 & -2.290 \\
\hline 3 & Panda & -0.296 & 1.352 & -2.585 \\
\hline 4 & singa & -0.995 & 1.499 & -2.609 \\
\hline 5 & badak & -0.296 & 1.352 & -2.585 \\
\hline 6 & karibu & 0.391 & 1.352 & -3.044 \\
\hline 7 & Gajah & -0.759 & 2.043 & -1.283 \\
\hline 8 & jaguar & -0.446 & 1.359 & -1.982 \\
\hline 9 & rubah & -0.881 & 1.352 & -4.554 \\
\hline 10 & Anjing liar & -0.095 & 1.370 & -2.631 \\
\hline 11 & serigala & 0.316 & 1.464 & -2.118 \\
\hline
\end{tabular}




\begin{tabular}{|r|l|l|l|l|}
12 & rusa & 0.169 & 1.180 & -3.129 \\
\hline 13 & $\begin{array}{l}\text { burung } \\
\text { unta }\end{array}$ & 1.118 & 0.624 & -2.162 \\
\hline & $\begin{array}{l}\text { Beruang } \\
\text { kutub }\end{array}$ & 1.497 & 0.831 & -3.351 \\
\hline 15 & Harimau & 1.791 & 0.682 & -4.066 \\
\hline 16 & Jerapah & 1.514 & 1.707 & -5.314 \\
\hline
\end{tabular}

Tabel 2 Tabel Rotasi Objek hewan berdasarkan sumbu x, y, z

\begin{tabular}{|c|c|c|c|c|}
\hline No & Hewan & $\mathrm{x}$ & $\mathrm{y}$ & $\mathrm{z}$ \\
\hline 1 & lynx & 0 & 0 & 0 \\
\hline 2 & zebra & 0 & 39.762 & 0 \\
\hline 3 & Panda & 0 & 38.923 & 0 \\
\hline 4 & singa & 0 & 92.271 & 0 \\
\hline 5 & badak & 0 & 110.370 & 0 \\
\hline 6 & karibu & 0 & 132.461 & 0 \\
\hline 7 & Gajah & 0 & -37.436 & 0 \\
\hline 8 & jaguar & -0.665 & 177.823 & 1.228 \\
\hline 9 & rubah & 0 & 33.640 & 0 \\
\hline 10 & $\begin{array}{l}\text { Anjing } \\
\text { liar }\end{array}$ & 1.042 & 141.25 & -1.283 \\
\hline 11 & serigala & 0 & 38.603 & 0 \\
\hline 12 & rusa & 0 & 61.592 & 0 \\
\hline 13 & $\begin{array}{l}\text { burung } \\
\text { unta }\end{array}$ & 0 & 95.824 & 0 \\
\hline 14 & $\begin{array}{l}\text { Beruang } \\
\text { kutub }\end{array}$ & 0 & -66.73 & 0 \\
\hline 15 & Harimau & 0 & -50.75 & 0 \\
\hline 16 & Jerapah & 0 & -27.44 & 0 \\
\hline 17 & $\begin{array}{l}\text { babi } \\
\text { hutan }\end{array}$ & 0 & -16.04 & 0 \\
\hline 18 & Kangguru & 0 & 5.078 & 0 \\
\hline
\end{tabular}

Tabel 3 Tabel Skala Objek hewan berdasarkan sumbu x, y, z

\begin{tabular}{|l|l|l|l|l|}
\hline No & Hewan & $\mathrm{x}$ & $\mathrm{y}$ & $\mathrm{y}$ \\
\hline 1 & lynx & 0.868 & 0.868 & 0.868 \\
\hline 2 & zebra & 1.800 & 1.176 & 0.913 \\
\hline 3 & Panda & 1.981 & 1.303 & 1.000 \\
\hline 4 & singa & 1.807 & 1.437 & 1.000 \\
\hline 5 & badak & 2.151 & 1.589 & 1.000 \\
\hline 6 & karibu & 2.802 & 1.991 & 1.045 \\
\hline 7 & Gajah & 5.860 & 3.049 & 1.982 \\
\hline 8 & jaguar & 1.223 & 0.949 & 0.818 \\
\hline 9 & rubah & 1.495 & 1.160 & 1.000 \\
\hline 10 & Anjing liar & 2.100 & 1.393 & 1.201 \\
\hline 11 & serigala & 1.583 & 1.229 & 1.059 \\
\hline 12 & rusa & 2.964 & 2.256 & 1.825 \\
\hline 13 & burung unta & 1.486 & 1.200 & 1.034 \\
\hline 14 & $\begin{array}{l}\text { Beruang } \\
\text { kutub }\end{array}$ & 3.288 & 2.185 & 1.884 \\
\hline 15 & Harimau & 1.788 & 1.388 & 1.196 \\
\hline
\end{tabular}

Untuk menghasilkan hasil yang maksimal maka ditambahkan Environment hutan. Untuk menambahkan environment hutan maka dibutuhkan sebuah source aframe environment component. Selain itu diperlukan atribut background pada scene dengan environment adalah forest. Selain Forest pada aframe environment component menyediakan beberapa environment antara lain : poison, default, tron, dream dll. Setelah ditambahkan environment maka diatur untuk transparent dari objek 2 Dimensi jika tidak diatur masalah transparantnya maka hasilnya akan seperti pada gambar 9

\section{Menambahkan Environment}

Untuk menghasilkan hasil yang maksimal maka ditambahkan Environment hutan. Untuk menambahkan environment hutan maka dibutuhkan sebuah source aframe environment component. Selain itu diperlukan atribut background pada scene dengan environment adalah forest. Selain Forest pada aframe environment component menyediakan beberapa environment antara lain : poison, default, tron, dream dll. Setelah ditambahkan environment maka diatur untuk transparent dari objek 2 Dimensi jika tidak diatur masalah transparantnya maka hasilnya akan seperti pada gambar 9 .

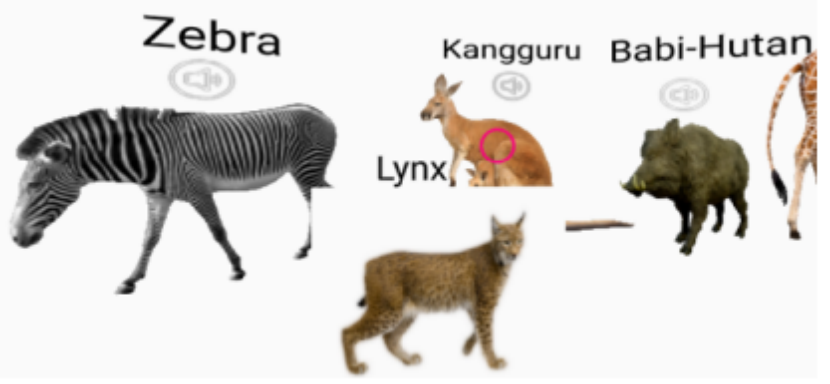

Gambar 9 Objek lynx yang menutupi objek kangguru dan zebra

Pada gambar 9 jika saat tidak diatur masalah transparantnya maka objek lynx akan menutupi objek zebra dan kangguru walaupun pada awalnya background dari objek hewan tersebut sudah transparant. Maka untuk mengatasi hal ini menambahkan beberapa atribut pada getObject3D dengan code seperti berikut:

<script> AFRAME.registerComponent ('alpha-test', \{
dependencies: ['material'], init: function () \{

this.el.getobject3D ('mesh') . material.alpha Test $=$

$0.5 ;\}$ ) ) $;<$ script $>$

Sehingga pada tag image $(<$ a-image $></$ a-image $>)$ ditambahkan atribut transparent dengan nilai true, alpa-test dengan nilai 0.5 dan hasilnya seperti pada gambar 10 .

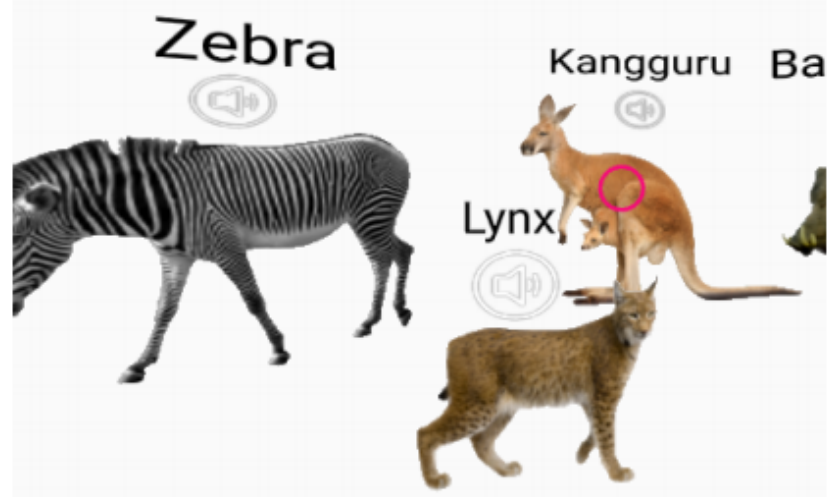

Gambar 10 hasil setelah ditambahkan beberapa atribut pada getObject3D 
Sehingga setelah ditambahkan environment forest seperti pada gambar 11 .

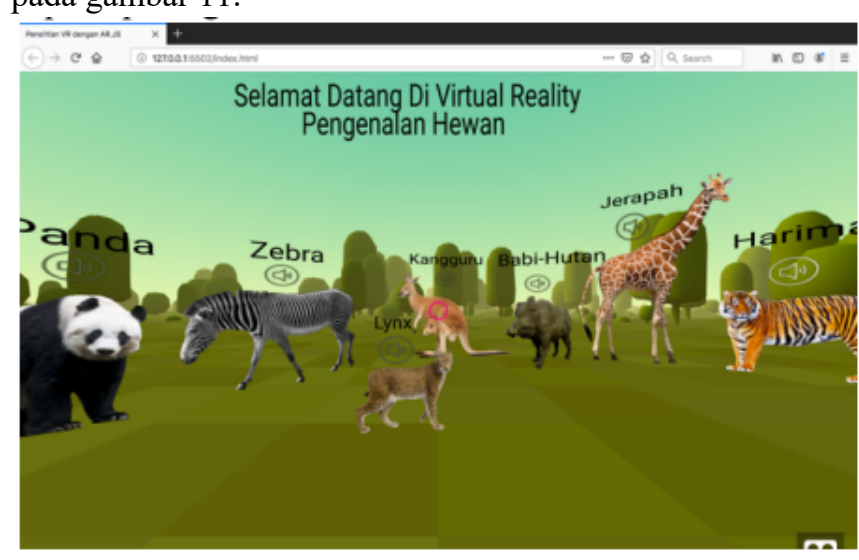

Gambar 11 hasil dari environment forest

\section{Menambahkan suara}

Untuk menambahkan suara pada aplikasi virtual reality pengenalan hewan ini menggunakan library howler.js. Untuk howler.js ini support file suara dengan extensi .wav, .mp3, .webm. Untuk penggunaan library howler.js ini menggunakan cara sprite object dimana perlu mengset offset dan duration dari sebuah source. Offset dan duration ini didefinisikan dalam miliseconds.

\section{E. Pengujian sistem menggunakan ngrok}

Pengujian sistem menggunakan ngrok, dimana ngrok ini digunakan agar user dapat mengakses localhost. Saat ngrok dijalankan maka ngrok akan membuat sebuah link yang akan mengarahkan ke localhost seperti pada gambar 12 alamat forwardingnya https://381e4e02.ngrok.io.

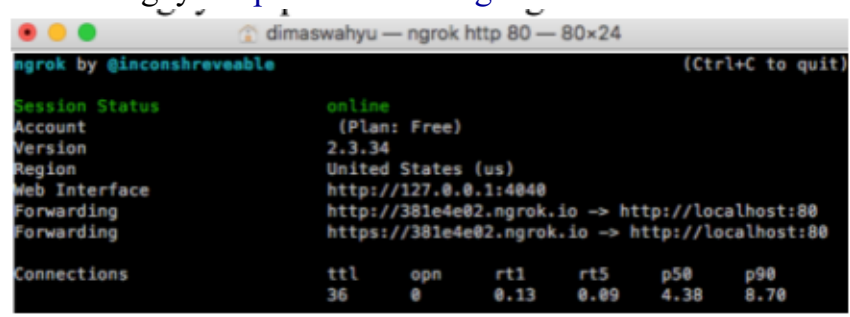

Gambar 12 ngrok berjalan

Jika browser pada membuka halaman forwading maka ngrok akan melakukan request objek-objek yang ada pada aplikasi virtual reality seperti pada gambar 13 .

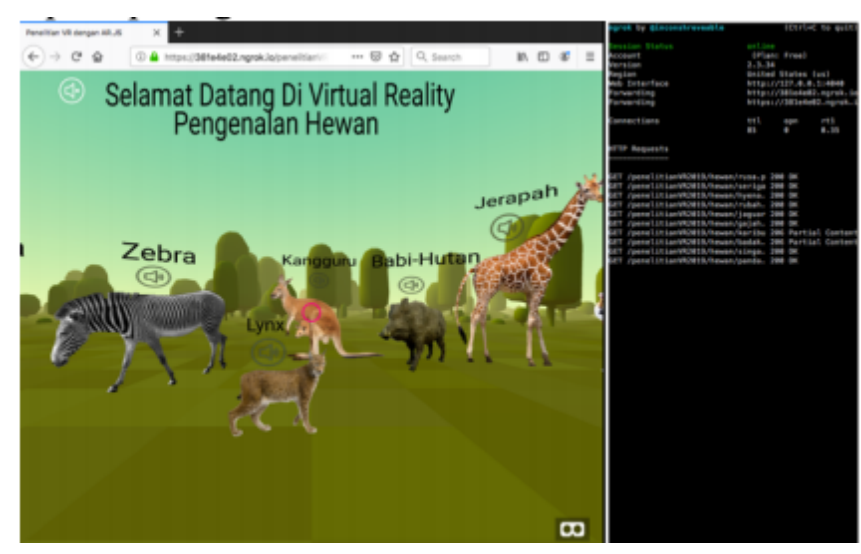

Gambar 13 alamat forwarding aplikasi VR
Jika dijalankan pada web mobile maka hasilnya seperti pada gambar 14.

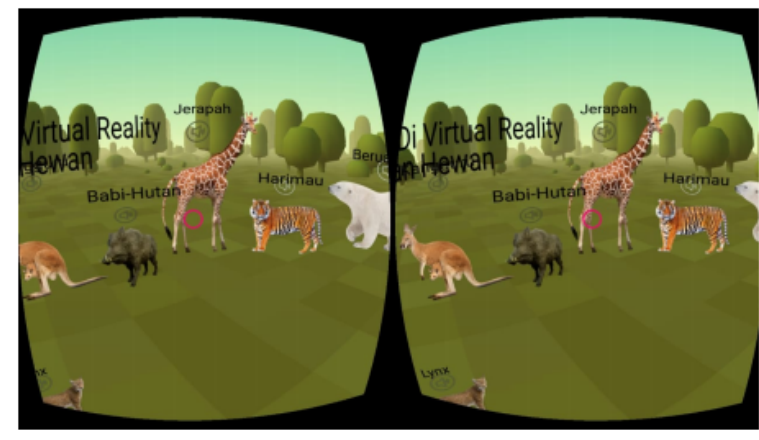

Gambar 14 Hasil pada mobile web

\section{KESIMPULAN DAN SARAN}

\section{A. Kesimpulan}

Kesimpulan dari penelitian ini adalah

1. Pada saat ngrok dijalankan dan dibuka di browser laptop atau PC tidak terjadi kendala, kursor berjalan baik tetapi pada saat dijalankan pada browser pada handphone terjadi kendala yaitu pergerakan kursor lambat

2. Pada saat ngrok dijalankan pada saat dibuka dibrowser pc ataupun laptop tampilan objek hewan sama dengan localhost tetapi pada saat dibuka pada handphone tampilan objek hewan dan text menjadi tidak sesuai dengan tampilan pada localhost

3. Suara pada hewan tidak terlalu jelas pada saat aplikasi virtual reality berjalan pada browser handphone

4. Framework A-Frame dapat digunakan untuk membuat aplikasi Virtual Reality yang berjalan pada sebuah web browser

B. Saran

Saran dari penelitian ini adalah

1. Perlu diset kembali posisi, rotasi dan skala objek hewan 2 dimensi agar tampilan pada handphone sesuai dengan tampilan pada localhost pada saat ngrok berjalan

2. Perlu adanya riset kembali mengenai objek 2 Dimensi dirubah menjadi objek 3 Dimensi

\section{Daftar Pustaka}

[1] Arsyad, Anzhar. 2006. media pembejaran, Jakarta:Rineka Cipta

[2] Cantor, Diego , Jones, Brandon (2012). WebGL beginner's guide. Pact Publishing

[3] Wibowo,Dimas Wahyu; Saputra, Pramana Yoga; Amalia, Eka Larasati;Ulfa,Farida, Penerapan Library AR.JS untuk pembuatan Augmented Reality sebagai media Pembelajaran Pengenalan hewan, SMARTICS Journal, Vol 4 no 2 Oktober 2018

[4] Ni Luh putu. Pentingnya penggunaan media pembelajaran untuk meningkatkan prestasi belajar siswa

[5] Setiawan, Firman. Aplikasi 3d virtual reality sebagai media pengenalan kampus politeknik negeri indramayu berbasis mobile. Jurnal informatika dan komputer (jiko) - vol. 2, no. 2, September 2017

[6] JavaScript Uncover. Panduan Belajar JavaScript untuk Pemula, DuniaIlkom, 2017 